\title{
DISCUSSION
}

\section{Maturing of contacts and ageing of silica sand}

\author{
RADOSLAW L. MICHALOWSKI*, ZHIJIE WANG $\dagger$, SRINIVASA S. NADUKURU‡, \\ GHOLAMREZA MESRI§ and THIERNO KANE§
}

\section{Contribution by G. Mesri and T. Kane}

Michalowski et al. (2018: p. 133) conclude that 'much less attention has been paid to the search for mechanisms causing the time effects'. They propose 'micro-fracturing' of textural features on the grain surfaces causing 'contact maturing' as the major contributor to time effects and thus to the ageing of silica sands.

In connection with the observed time-dependent postdensification ageing of the silica sand deposit in the Jabba project in Nigeria, and also ageing of clean quartz sands in the laboratory, Mesri et al. (1990: p. 1112) proposed at constant effective vertical stress and increasing time 'continued rearrangement of sand particles resulting in an enhanced macrointerlocking of sand grains and microinterlocking of grain surface roughness'. The significant sand grain surface roughness has been characterised by scanning electron micrographs in Fig. 16 of Mesri et al. (1990), Figs 1-3 of Mesri \& Vardhanabhuti (2007) and Fig. 1 of Mesri \& Vardhanabhuti (2009), for particles of seven different natural sand deposits.

Mesri \& Vardhanabhuti (2009) characterised sand particle damage during laterally constrained or isotropic compression, by level I damage as abrasion or grinding of particle surface asperities, level II damage as breaking or crushing of particle surface protrusions and sharp particle corners and edges, and level III damage as fracturing, splitting or shattering of particles. The observed compression behaviour of a large number of sand deposits was described by Mesri \& Vardhanabhuti (2009) in terms of types A, B and $\mathrm{C}$ void ratio against effective vertical stress relationships. In type A compression behaviour, at low effective vertical stresses, small particle movements further engage particle surface roughness and enhance interparticle locking. There is minor or small level I and level II particle damage. In type C compression behaviour, significant level I and level II particle damage begin at low effective vertical stresses and continue with or without gradual level III particle damage at higher effective vertical stresses. The type B compression behaviour represents a transition between type $\mathrm{A}$ and type $\mathrm{C}$ compression behaviours.

In explaining the observed direct interrelationship between compressibility with time and compressibility with effective vertical stress, leading to the $C_{\alpha} / C_{\mathrm{c}}$ law of compressibility (Mesri, 1987), Mesri \& Godlewski (1977) proposed no difference between the mechanisms of volume change during the increase in external effective vertical stress and those operating with time at constant effective vertical stress.

\footnotetext{
* Department of Civil and Environmental Engineering, University of Michigan, Ann Arbor, MI, USA (Orcid:0000-0002-9557-4802).

$\dagger$ Formerly University of Michigan; now Country Garden Holdings Co. Ltd, Guangdong, P. R. China.

+ Formerly University of Michigan; now Geosyntec Consultants, Keenesaw, GA, USA.

$\S$ University of Illinois, Urbana-Champaign, IL, USA
}

In all three types of sand compression behaviour, some level of particle damage during the increase in effective vertical stress was proposed by Mesri \& Vardhanabhuti (2009). Thus, particle damage at a decreasing rate with time is expected to continue at constant effective vertical stress; this is not inconsistent with the Michalowski et al. (2018) proposal of micro-fracturing with time at constant load.

The main interparticle time-dependent ageing mechanism at particle contacts, contributing to increased stiffness of sand particle assemblies, according to Mesri et al. (1990), is micro-interlocking of sand grain surface roughness. Micro-fracturing may facilitate micro-interlocking of surface roughness; however, it is not obvious as to how micro-fracturing alone may have beneficial effects on sand properties (Terzaghi et al. (1996), e.g. pp. 146-151), unless by 'contact maturing' Michalowski et al. (2018) mean enhanced primary valence bonding (Bowden \& Tabor, 1964) at grain contacts.

In sand grain assemblies, interparticle contact interaction is aided by the freedom of particles to move in two or three directions. This freedom of movement may not be available in the Michalowski et al. (2018) double-grain or single-grain loading experiments. The discussion contributors also wish to point out that the $C_{\alpha} / C_{\mathrm{c}}$ law of compressibility, which has explained many implications of compression with time at constant effective stress (Mesri, 1987), has been used to interpret in lateral compression and constant effective vertical stress, time-dependent changes in effective horizontal stress (Mesri \& Hayat, 1993; Mesri \& Vardhanabhuti, 2009; Mesri \& Wang, 2016) and time-related increases in the shaft resistance of piles in sand (Mesri \& Smadi, 2001).
Authors' reply
The authors thank Professor Mesri and Mr Kane for pointing out the contributions of their research group to the subject matter. Mesri and Kane do not dispute any of the findings in the paper, and remark that the earlier contri- bution in Mesri \& Vardhanabhuti (2009) 'is not inconsistent with the Michalowski et al. (2018) proposal of micro- fracturing with time at constant load'. They comment on the role of 'continued rearrangement of sand particles' in the compression process, and the effect of 'small particle movement' that engages surface roughness and enhances interparticle locking. Indeed, these are components of the process leading to an increase in the contact stiffness, and, consequently, macroscopic stiffness of sand, often referred to as sand ageing. While this time-dependent grain rearrangement (also referred to as structuration) is a part of the secondary compression process, the authors view ageing as a process initiated on intergranular contacts. The small periodic rearrangement of grains and increase in sand stiffness are the consequences (or a manifestation) of the ageing process, but the evidence suggests that neither would occur without static fatigue (or maturing) at the intergranular contacts. 


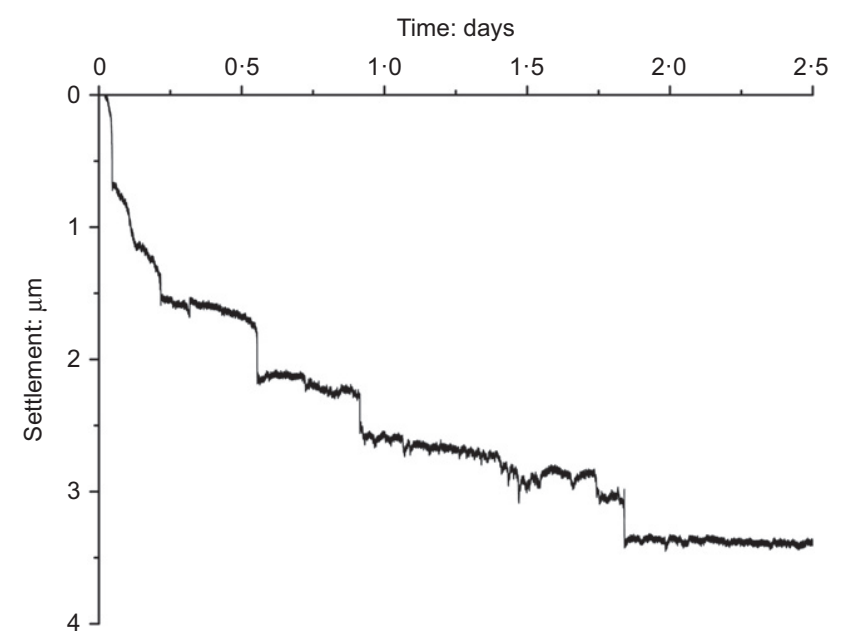

Fig. 12. Time-settlement curve of an oedometric air-dry Ottawa sand specimen $(50 \cdot 8 \mathrm{~mm}$ high) under constant vertical load of $230 \mathrm{kPa}$ in the first $2 \cdot 5$ days (data from Fig. 11(b))

Readers might find it interesting to look at the process of grain rearrangement, which is manifested as a settlement of oedometric sand specimens subjected to constant vertical loads. The graph in Fig. 12 illustrates the settlement of a $50.8 \mathrm{~mm}$ tall oedometric specimen of air-dry Ottawa 20-30 sand loaded with $230 \mathrm{kPa}$. This is the first 2.5 days of the time-dependent process shown in Fig. 11(b) of Michalowski et al. (2018). Although there is some noise in the signal, the settlement appears to have distinct steps of about $0.5 \mu \mathrm{m}$, which are likely to be associated with the structuration events. An even more distinct step-wise settlement curve is illustrated in Fig. 13. This is a result recorded during the settlement of a $60 \mathrm{~cm}$ tall column of sand $(30 \mathrm{~cm}$ dia.) under its own weight, in the first 2 days after sand deposition; the steps are now of the order of tens of microns (after Nadukuru et al., 2012).

The first part of the paper by Michalowski et al. (2018) focused on the response of an individual contact to applied load. A sand grain in an assembly of grains, however, is subjected to a different loading pattern. First, an individual grain within an assembly has a larger number of contacts (several), and the loads on the contacts vary in time, even under constant external load. This is because of the non-uniform evolution of the stiffness at different contacts causing redistribution of the forces in the force chains. As the grains are kinematically constrained in a stable assembly, they cannot move, unless the redistribution of forces and the minute geometrical changes associated with micro-fracturing of textural features on grain surfaces produce a mechanism in an originally stable assembly of grains. This mechanism gives rise to structuration events, manifested as 'steps' in the settlement plotted against time function, seen as vertical portions of the settlement curve (e.g. at 1.25 days in Fig. 13). The horizontal portions (e.g. between 0.3 and 0.8 days) are not periods of 'rest'; to the contrary, they are periods of contact maturing or contact ageing, but the next structuration event will be possible only when enough contacts have matured, enabling an instability in the grain assembly (a mechanism) to be triggered. This is a plausible explanation of the settlement steps in Figs 12 and 13. The process of settlement under constant load is then a sequence of instabilities. The 'continued rearrangement of sand particles' is a step-wise process, and it is a result of ageing rather than the cause of it.

If the contacts were not subjected to static fatigue (at least not on the timescale comparable to that for silica sand

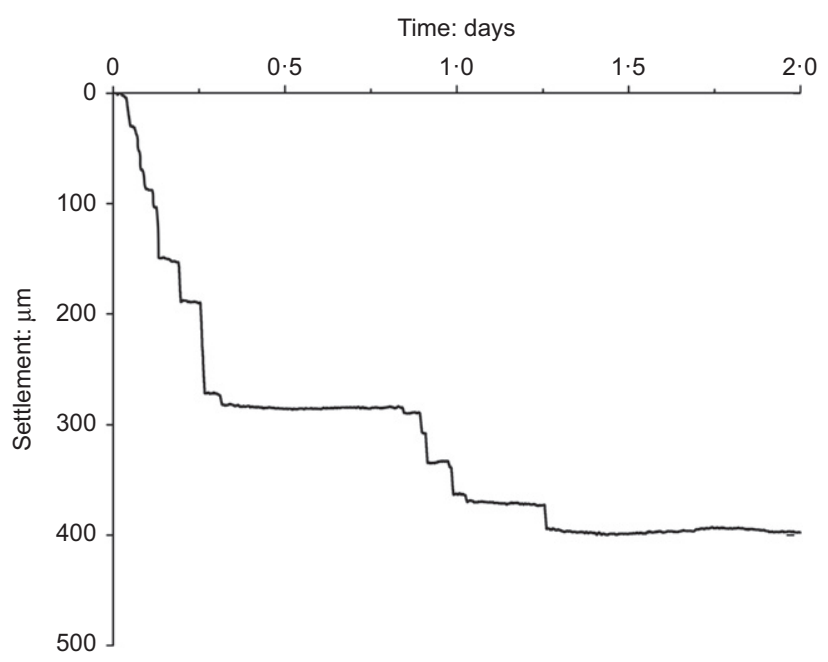

Fig. 13. Step-wise time-settlement curve of a $60 \mathrm{~cm}$ tall column of Ottawa sand under its own weight

grains), the oedometric specimen would not display timedependent settlement, and the radial stress would remain constant in the specimen, indicating no changes in the macroscopic stiffness. This expectation was confirmed using the test with an assembly of stainless steel spheres, with the results illustrated in Fig. 10 of Michalowski et al. (2018). The experimental evidence suggests that the ageing process is triggered by the contact static fatigue (or contact maturing).

\section{REFERENCES}

Bowden, F. P. \& Tabor, D. (1964). The friction and lubrication of solids: part $i$ and part II. Oxford, UK: Oxford University Press.

Mesri, G. (1987). Fourth law of soil mechanics: a law of compressibility. Proceedings of an international symposium on geotechnical engineering of soft soils, Mexico City, Mexico, vol. 2, pp. 179-187.

Mesri, G. \& Godlewski, P. M. (1977). Time and stress compressibility interrelationship. J. Geotech. Engng Div., ASCE 103, No. GT5, 417-430.

Mesri, G. \& Hayat, T. M. (1993). The coefficient of earth pressure at rest. Can. Geotech. J. 30, No. 4, 447-666.

Mesri, G. \& Smadi, M. M. (2001). Discussion: Time-related increases in shaft capacities of driven piles in sand. Géotechnique 51, No. 5, 475-476, https://doi.org/10.1680/ geot.2001.51.5.475.

Mesri, G. \& Vardhanabhuti, B. (2007). The coefficient of earth pressure at rest of sands subjected to vibration. Can. Geotech. J. 44, No. 10, 1242-1263.

Mesri, G. \& Vardhanabhuti, B. (2009). Compression of granular materials. Can. Geotech. J. 46, No. 4, 369-392.

Mesri, G. \& Wang, C. (2016). Experimental characteristics of coefficient of earth pressure at rest, stiffness and contact force distribution of sand during secondary compression and rebound. Discussion. Can. Geotech. J. 53, No. 10, 1760-1761.

Mesri, G., Feng, T. W. \& Benak, J. M. (1990). Postdensification penetration resistance of clean sand. J. Geotech. Engng 116, No. 7, 1095-1115.

Michalowski, R. L., Wang, Z. \& Nadukuru, S. S. (2018). Maturing of contacts and ageing of silica sand. Géotechnique 68, No. 2, 133-145, https://doi.org/10.1680/jgeot.16.P.321.

Nadukuru, S. S., O'Connor, S. M. \& Michalowski, R. L. (2012). Static fatigue and delayed effects in sand and lunar regolith. In Proceedings of ASCE earth and space 2012: engineering, science, construction, and operations in challenging environments (eds K. Zacny, R. B. Malla and W. Binienda), pp. 256-263. Reston, VA, USA: American Society of Civil Engineers.

Terzaghi, K., Peck, R. B. \& Mesri, G. (1996). Soil mechanics in engineering practice, 3rd edn. New York, NY, USA: Wiley. 